\title{
The effect of single dose of preoperative dexamethasone on postoperative nausea and vomiting after laparoscopic cholecystectomy: a randomized, double-blind, placebo-controlled study
}

\author{
Authors \\ C.P. Pandey ${ }^{1}$, Gopal Krishan ${ }^{2 *}$, Atul Shishodia ${ }^{3}$, C.G.S. Chauhan ${ }^{1}$, Amit Kukreti ${ }^{3}$ \\ Gaurav Kumar ${ }^{4}$ \\ ${ }^{1}$ Professor, Department of General Surgery, RMCH Bareilly \\ ${ }^{2}$ Assistant Professor, Department of Anaesthesiology, RMCH Bareilly \\ ${ }^{3}$ Junior Resident, Department of General Surgery, RMCH Bareilly \\ ${ }^{4}$ Junior Resident, Department of Anaesthesiology, RMCH Bareilly \\ *Corresponding Author \\ Dr Gopal Krishan \\ Assistant Professor, Department of Anaesthesiology, RMCH Bareilly, UP, India \\ Email: gkgsvm@yahoo.com, Telephone No.:8979341741
}

\begin{abstract}
Objective: To study the efficacy of single dose of preoperative dexamethasone in the prevention of postoperative nausea and vomiting in patients undergoing laparoscopic cholecystectomy.

Materials and Methods: 110 patients were randomized in two equal groups. Each of the groups received either $2 \mathrm{ml}(8 \mathrm{mg})$ intravenous dexamethasone (Group A) or $2 \mathrm{ml}$ intravenous normal saline as placebo (Group B).

Results: 6 patients (14.5\%) in group A and 19 patients (34.5\%) in group B had postoperative nausea and vomiting in first 6 hours whereas 2 patients (3.6\%) in group $A$ and 5 patients (9.0\%) in group B had postoperative nausea and vomiting in 6-24 hours.

Conclusion: Preoperative dexamethasone improves the surgical outcome by reducing disabling symptoms of nausea and vomiting without apparent side-effects. So we suggest that single dose of preoperative dexamethasone should be used as a routine in patients undergoing elective laparoscopic cholecystectomy.

Keywords: Cholelithiasis, Dexamethasone, Laparoscopic cholecystectomy, Postoperative nausea and vomiting.
\end{abstract}

\section{Introduction}

Laparoscopic cholecystectomy has become the most frequently performed surgical procedure worldwide for symptomatic cholelithiasis. Despite the fact that it is a safe procedure, complications such as nausea, vomiting, and pain are frequent during the postoperative period, and are among the main causes of patient complaints and dissatisfaction $^{[1]}$ The origin of postoperative nausea and vomiting after laparoscopic cholecystectomy is not entirely clear. Female sex, prolonged carbon dioxide insufflation, length of 
procedure, use of nitrous oxide, the utilization of slightly hypoxic mixtures during anaesthesia and postoperative opioid analgesic administration have been suggested as potential risk factors. ${ }^{[2,3]}$ Postoperative nausea and vomiting can lead to serious complications such as aspiration, dehydration, electrolyte disturbances and disruption of incision site. It can also increase the cost of treatment. Another impact of postoperative nausea and vomiting, is its unpleasent effect on patients. Some patients regard it as more disabling than the operation itself. Dexamethasone, a corticosteroid, has welldefined antiemetic, anti-inflammatory, immunomodulating and analgesic effects, in addition to having few side effects when administered in small doses. It is widely used for controlling nausea and vomiting after chemotherapy and surgical procedures including laparoscopic cholecystectomy.

The objective of this randomized, double-blind, placebo-controlled study was to assess the effectiveness of single dose of preoperative dexamethasone in the prophylaxis of postoperative nausea and vomiting after laparoscopic cholecystectomy.

\section{Materials and Methods}

After approval from the institutional ethical committee this prospective, randomized, double blind, placebo-controlled study was conducted in the department of surgery, Rohilkhand Medical College and Hospital, Bareilly, Uttar Pradesh, India. A total of 110 patients of either sex, with ASA grade I or II, aged 18 yrs - 50 years were enrolled for the study. The patients were randomly assigned using "computer generated random number table" to one of the following groups:

Group A $(n=55)$ : Were scheduled to receive dexamethasone $2 \mathrm{ml}(8 \mathrm{mg})$ intravenously.

Group B $(n=55)$ : Were scheduled to receive normal saline $2 \mathrm{ml}$ intravenously.

These drugs were prepared by the staff nurse on duty and given by the doctor on duty, two hours before the starting of the operation. Pre-anesthetic checkup was done and patient was informed about the procedure. Tab. alprazolam $0.5 \mathrm{mg}$ was given evening before surgery and at $5 \mathrm{Am}$ in the morning with a sip of water. IV line was secured with 18 Gauze IV cannula and IV fluid was started. The patient was connected to all the standard monitors to record pulse rate, $\mathrm{O}_{2}$ saturation, non invasive blood pressure, end tidal carbon dioxide and electrocrdiogram. Premedication with inj. Midazolam $0.05 \mathrm{mg} / \mathrm{kg}$ body weight before the procedure was given.

After pre oxygenation for 3 minutes, with $100 \%$ oxygen, anaesthesia was induced with injection propofol $2.0 \mathrm{mg} / \mathrm{kg}$ and 3 minutes after injection of vecuronium $0.1 \mathrm{mg} / \mathrm{kg}$, direct laryngoscopy was performed and the patient was intubated with a well lubricated, appropriate sized poly vinyl chloride cuffed endotracheal tube. Bilateral air entry was checked and the tube was firmly secured and controlled ventilation was started. Anaesthesia was maintained with $30 \%$ oxygen, $70 \%$ nitrous oxide, $0.8 \%$ isoflurane and intermittent boluses of inj. vecuronium $0.02 \mathrm{mg} / \mathrm{kg}$.

Pneumoperitoneum was created with open technique and laparoscopic cholecystectomy was performed using two ports of $10 \mathrm{~mm}$ and two of 5 $\mathrm{mm}$, maintaining a $12 \mathrm{~mm} \mathrm{Hg}$ intraabdominal pressure. At the end of procedure, the carbon dioxide was carefully evacuated from the abdomen. Monitoring of vital parameters such as heart rate, systolic blood pressure, diastolic blood pressure, mean arterial pressure and oxygen saturation were recorded at fixed intervals, i.e. preoperative, after intubation and then at 15, 30, 45, 60, 75 and 90 minutes following intubation.

At the end of surgery, all the anaesthetic agents were stopped, $100 \%$ oxygen was given and oropharyngeal suction was done. After returning of respiratory efforts residual neuromuscular blockade was reversed by injection neostigmine $0.04 \mathrm{mg} / \mathrm{kg}$ and Injection glycopyrrolate 0.02 $\mathrm{mg} / \mathrm{kg}$ intravenously. Episodes of nausea, and vomiting were registered by the doctor on duty in first 24 hours after operation. 
When respiration became normal and tidal volume was adequate, extubation was done. After extubation, patients were oxygenated with $100 \%$ for 5 minutes and then shifted to postoperative ward. All the results were compiled, compared and analysed statistically by using the statistical package for the social science (SPSS 22.0, IBM, New York, USA). The data was compiled using Microsoft Excel Sheet (Windows 2010). For each variable the mean and standard deviation were calculated.

Numerical variables were compared between the groups by independent sample $t$-test if normally distributed and by Mann-Whitney U-test if skewed. Chi-square test and Fisher's exact test were used to compare the categorical variables between groups. All statistical analysis was twotailed, and a $p$-value $<0.05$ was considered significant and $<0.001$ was considered highly significant.

\section{Observations}

Both the groups were comparable in the terms of Age, Gender, Body Mass Index, ASA Grade and duration of surgery and no statistically significant difference was found ( $p$-value >0.05) (Table-1). 6 patients $(14.5 \%)$ in group A and 19 patients $(34.5 \%)$ in group B had postoperative nausea and vomiting in first 6 hours whereas 2 patients $(3.6 \%)$ in group A and 5 patients $(9.0 \%)$ in group $\mathrm{B}$ had postoperative nausea and vomiting in 6-24 hours (Table-2).

Mean pulse rate was comparable in both the groups on starting of the procedure. Pulse rate changes during the entire intraoperative period were statistically not significant in both the groups ( $p$-value > 0.05) (Figure-1).

Mean systolic blood pressure was comparable in both the groups on starting of the procedure. Systolic blood pressure changes during the entire intraoperative period were statistically not significant in both the groups ( $p$-value $>0.05$ ) (Figure-2).

Mean Diastolic blood pressure was comparable in both the groups on starting of the procedure. Diastolic blood pressure changes during the entire intraoperative period were statistically not significant in both the groups ( $p$-value $>0.05$ ) (Figure3).

Table 1 Comparison of Demographic Data

\begin{tabular}{|l|c|c|c|}
\hline Parameters & Group A (n=55) & $\begin{array}{c}\text { Group B } \\
(\mathrm{n}=55)\end{array}$ & $p$-value \\
\hline Age (Years) & $31.70 \pm 7.8$ & $32.30 \pm 8.7$ & $>0.05$ \\
\hline Body Mass Index & $23.59 \pm 2.9$ & $22.82 \pm 3.2$ & $>0.05$ \\
\hline Gender (M/F) & $32 / 23$ & $34 / 21$ & $>0.05$ \\
\hline ASA (I/II) & $44 / 11$ & $46 / 09$ & $>0.05$ \\
\hline $\begin{array}{c}\text { Duration of surgery } \\
\text { (Minutes) }\end{array}$ & $67.83 \pm 9.5$ & $78.09 \pm 7.8$ & $>0.05$ \\
\hline
\end{tabular}

Table 2: Post opeative nausea and vomiting

\begin{tabular}{|l|c|c|c|}
\hline Variables & Group A $(\mathrm{n}=55)$ & Group B $(\mathrm{n}=55)$ & $p$-value \\
\hline 0-6 HOURS AFTER SURGERY & 8 & 19 & $<0.001$ \\
\hline 6-24 HOURS AFTER SURGERY & 2 & 5 & $<0.001$ \\
\hline
\end{tabular}




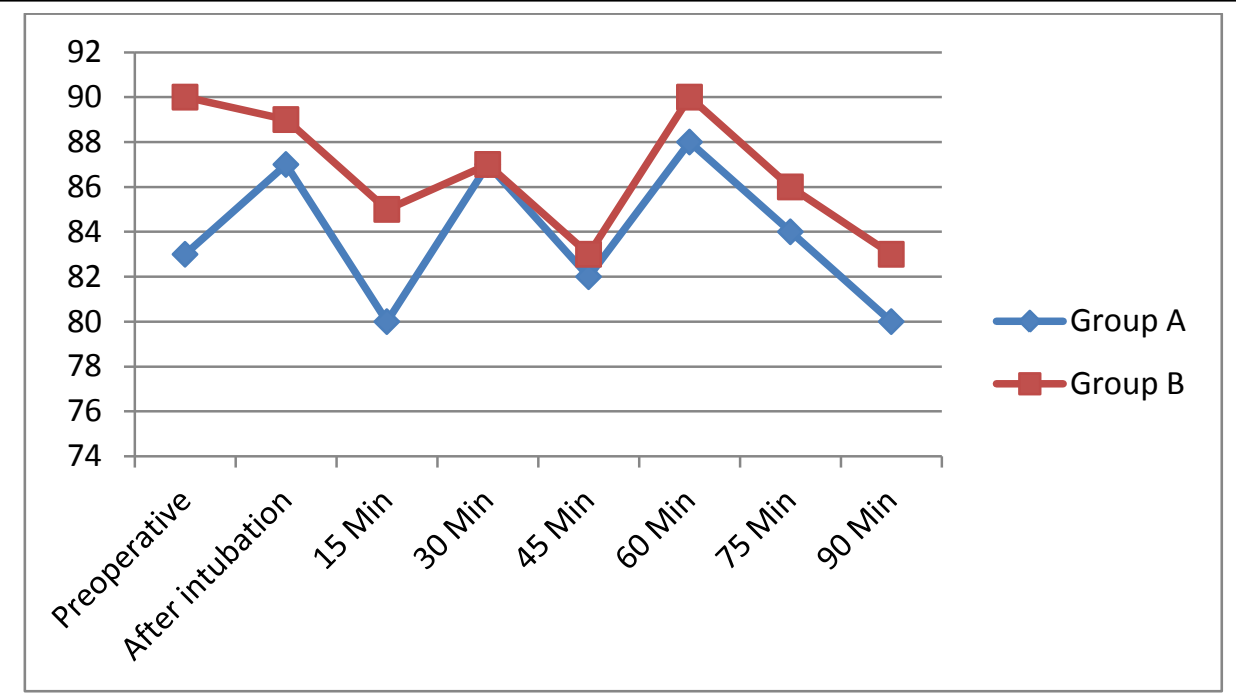

Figure - 1 Comparison of Mean Heart Rate (HR) in Group A and Group B

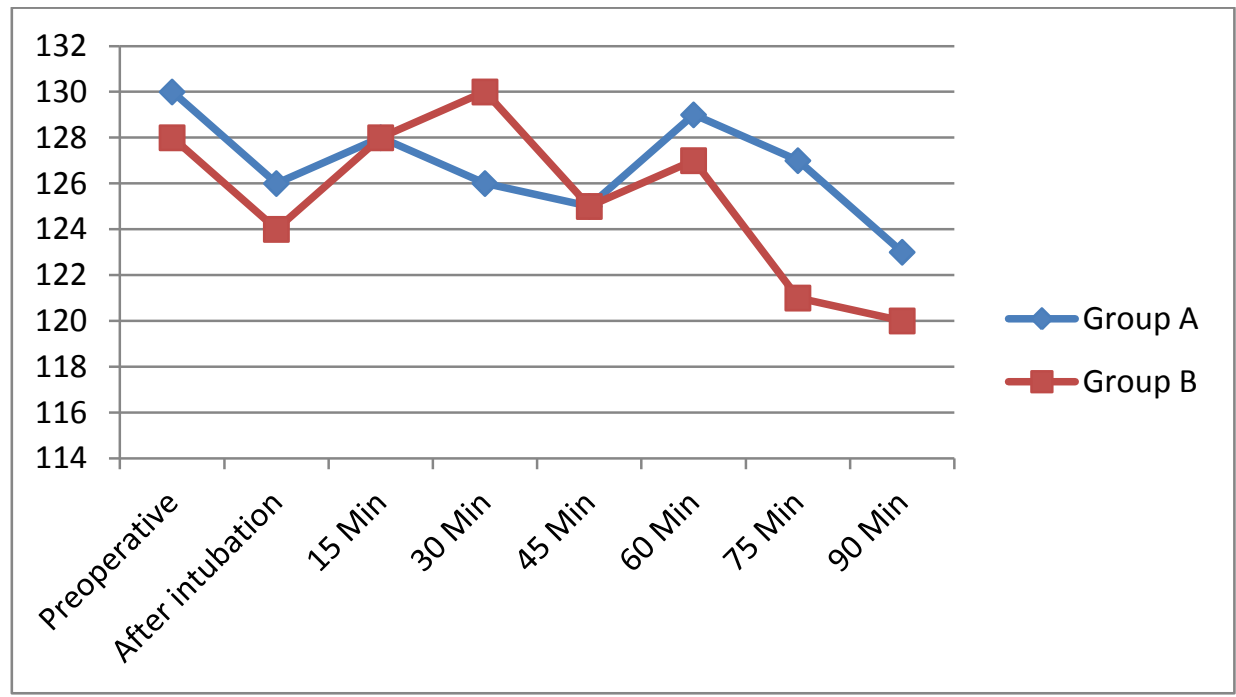

Figure - 2 Comparison of Mean Systolic Blood Pressure (SBP) in Group A and Group B

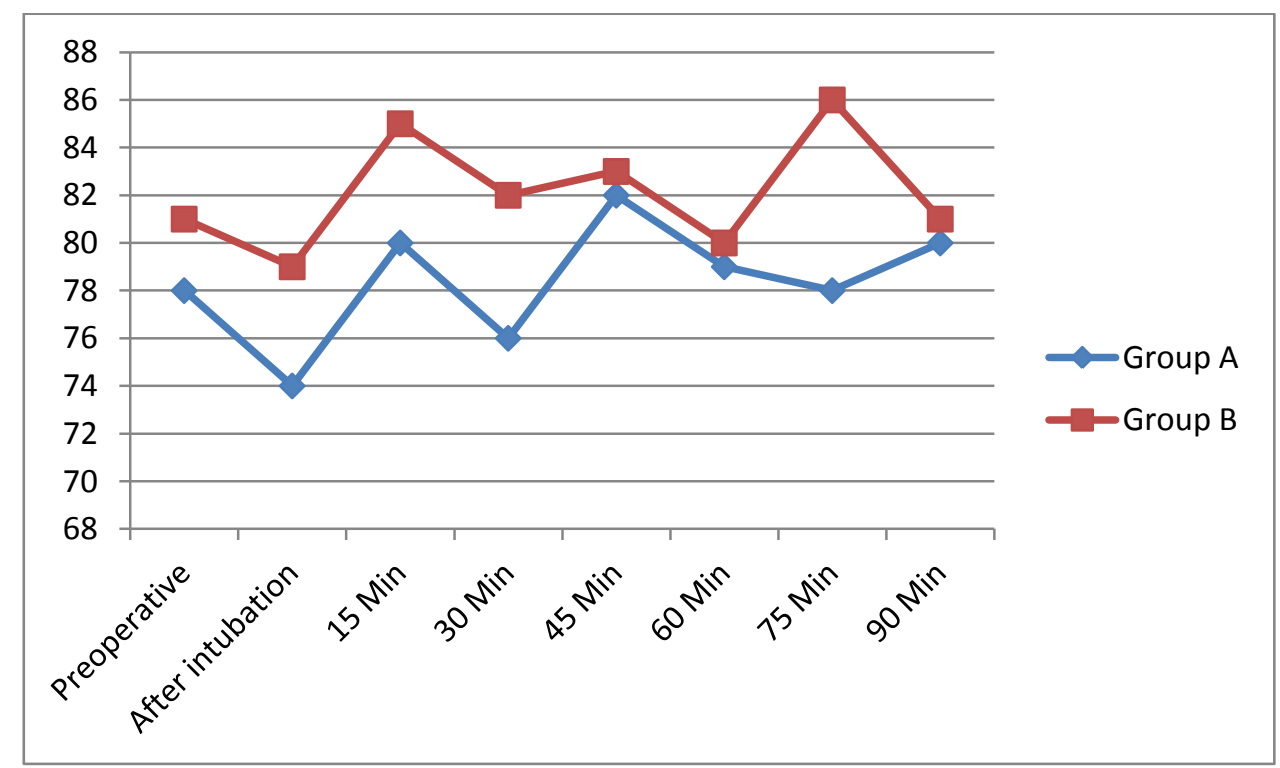

Figure - 3 Comparison of Mean Diastolic Blood Pressure (DBP) in Group A and Group B 


\section{Discussion}

Now a day's laparoscopic cholecystectomy has almost replaced open cholecystectomy because laparoscopic surgeries have been claimed to reduse the metabolic, hormonal, inflammatory, and immune responses related to surgical trauma. It reduces duration of hospital stay and overall cost of surgery. Nonetheless, a high incidence of nausea and vomiting, the main reasons for extended hospital stays, is reported in the postoperative period. ${ }^{[4]}$ Nausea and vomiting after a laparoscopic cholecystectomy are caused by multiple factors, depending especially on intraabdominal manipulation and formation of pneumoperitoneum, which stretches the peritoneum and irritates the diaphragm and viscera. ${ }^{[5]}$ Other causes of Postoperative nausea and vomiting after laparoscopic cholecystectomy includes pharyngeal stimulation due to tracheal stimulation, emetogenic anaesthetic agents used, pain, opioid analgesic agents used, hypoxia, hypotension, vestibular disturbances and psychological factors. There are certain factors which can predispose patients to postoperative nausea and vomiting, like age (more in children), gender (more in females), history of previous nausea and vomiting, history of motion sickness, long duration of operation and depth of anaesthesia, carbon dioxide retention, rough handling, lack of anaesthetist's skill, type of surgical procedure and number of visitors during recovery. ${ }^{[6]}$ Antiemetics currently prescribed for PONV, are serotonin subtype 3 antagonists (e.g., ondansetron and granisetron), anticholinergics, antihistamines and dopamine receptor antagonists. These may have side effects, such as sedation, dry mouth, restlessness, changes in arterial blood pressure, and extrapyramidal symptoms. Dexamethasone, a corticosteroid, is an inexpensive and effective antiemetic drug, with minimal side effects after a single-dose administration. ${ }^{[7-9]}$ The mechanism by which glucocorticoids alleviate these complications is not fully understood, but the effects are probably centrally mediated through inhibition of the prostaglandin synthesis and inhibition of the release of endogenous opioids, serotonergic inhibition in the gastrointestinal tract, and decrease in inflammation of the surgical site, reducing parasympathetic impulses to the area postrema. ${ }^{[10-12]}$

Dexamethasone was first used as an antiemetic in patients receiving cancer chemotherapy in 1981 . ${ }^{[13]}$ Recently, dexamethasone has been reported to be effective in preventing PONV in patients undergoing tonsillectomy, thyroidectomy, abdominal hysterectomy and laparoscopic cholecystectomy. The commonly used dose is 8 to $10 \mathrm{mg}$ but the minimal effective dose, as suggested by Asad Ali Shah et al for postoperative nausea and vomiting in patients undergoing thyroidectomy was $5 \mathrm{mg}$. ${ }^{\text {[14] }}$

Several randomized controlled trials have shown that single preoperative dose of dexamethasone is effective in reducing postoperative nausea and vomiting and antiemetic requirement after laparoscopic cholecystectomy.

Amer Riaz Bhutta et al in a study randomized 100 patients either in saline group receiving $2 \mathrm{ml}$ intravenous normal saline or dexa group receiving $2 \mathrm{ml}$ intravenous dexamethasone and concluded that preoperative dexamethasone improves surgical outcome by reducing postoperative nausea and vomiting without apparent side effects. [15]

J.J.Wang et al in a study on 90 patients found that a single dose of $8 \mathrm{mg}$ preoperative intravenous dexamethasone reduces the incidence of postoperative nausea and vomiting after laparoscopic cholecystectomy. ${ }^{[16]}$

Ahmadreza Mohtadi et al in a double blind prospective study on 122 patients aged 18-60 years undergoing laparoscopic cholecystectomy concluded that single dose of intravenous dexamethasone reduces incidence of postoperative nausea and vomiting. ${ }^{[17]}$

Like our conclusion, Bis Gaard $\mathrm{T}$ et al. also concluded that, preoperative Dexamethasone reduces pain, fatigue, nausea, vomiting and duration of convalescence in patients undergoing 
laparoscopic cholecystectomy, as compared to placebo and they recommend the routine use of single dose of preoperative dexamethasone in patients undergoing laparoscopic cholecystectomy [18]

In a study Feo CV et al. randomized 101 patients to receive either Dexamethasone $8 \mathrm{mg}$ (treatment group) or saline (control group), the frequency of postoperative nausea and vomiting in the treatment group was found significantly less as compared to placebo group $(p<0.001){ }^{[19]}$

In contrast to our study, Ionescu D et al. reported postoperative nausea and vomiting in $20 \%$ of patients who received preoperative dexamethasone as prophylaxis undergoing cholecystectomy and does not found any benefit in comparison to placebo. ${ }^{[20]}$ Kashmiri Z A et al. used dexamethasone $8 \mathrm{mg}$ in patients undergoing laparoscopic cholecystectomy just before induction of anaesthesia. In their study, $27 \%$ of patient experienced postoperative nausea and vomiting during first 12 hours and 30\% patients reported nausea and vomiting in next 12 hours. [21]

Wakasuqi $\mathrm{M}$ et al. in a large scale multicenter randomized double blind placebo controlled trial in Japan concluded that routine use of preoperative dexamethasone for postoperative nausea and vomiting after elective laparoscopic cholecystectomy was not shown to have any clinical advantage. ${ }^{[22]}$

The difference in their results could be due to use of different anaesthetic techniques, use of opioids and other analgesics in postoperative period, difference in patients population (male/female), duration of anaesthesia and duration of surgery.

\section{Conclusion}

Dexamethasone improve the surgical outcome by reducing disabling symptoms of nausea and vomiting without any side-effects. So single dose of preoperative dexamethasone may be used as a routine in patients undergoing elective laparoscopic cholecystectomy.

\section{References}

1. Madsen MR, Jensen KE. Postoperative pain and nausea after laparoscopic cholecystectomy. Surg Laparosc Endosc. 1992;2:303-5.

2. Apfel CC, Laara E, Koivuranta M, Greim C-A, Roewer N. A simplified risk score for predicting postoperative nausea and vomiting: conclusions from crossvalidations between two centers. Anesthesiology. 1999;91:693-700.

3. Kovac AL. Prevention and treatment of postoperative nausea and vomiting. Drugs. 2000;59:213-43.

4. Bisgaard T, Klarskov B, Rosenberg J, Kehlet H. Factors determining convalescence after uncomplicated laparoscopic cholecystectomy. Arch Surg. 2001; 136:917-21.

5. Watcha M F, White PF. Postoperative nausea and vomiting; its etiology, prevention and treetment .Anesthesiology 1992;77:162-84.

6. Ashfaque M. Prevention of postoperative nausea and vomiting:a review of causative factors and management. Med Channel 1998; 4:43-52.

7. Wang JJ, Ho ST, Liu YH, et al. Dexamethasone reduces nausea and vomiting after laparoscopic cholecystectomy. Br J Anaesth 1999;83:772-5.

8. Wang JJ, Ho ST, Lee SC, et al. The use of dexamethasone for preventing postoperative nausea and vomiting in females undergoing thyroidectomy: a dose-ranging study. AnesthAnalg 2000;91:1404-7.

9. Sehine I, Nishiwaki Y, Kakinuma R, et al. Phase II study of high-dose dexamethasone-based association in acute and delayed high-dose cisplatin-induced emesis: study 9413. Br J Cancer 1997; 76:90-2.

10. Fujii Y. The utility of antiemetics in the prevention and treatment of postoperative 
nausea and vomiting in patients scheduled for laparoscopic cholecystectomy. Curr Pharm Des. 2005;11:3173-83.

11. Henzi I, Walder B, Tramer MR. Dexamethasone for the prevention of postoperative nausea and vomiting: a quantitative systematic review. Anesth Analg. 2000;90:186-94.

12. Elhakim M, Nafie M, Mahmoud K, Atef A. Dexamethasone $8 \mathrm{mg}$ in combination with ondansetron $4 \mathrm{mg}$ appears to be the optimal dose for the prevention of nausea and vomiting after laparoscopic cholecystectomy. Can J Anaesth. 2002;49:922-6.

13. Aapro MS, Alberts DS. Dexamethasone as an antiemetic in patients treated with cisplatin. N Engl J Med 1981; 305: 520.

14. Asad Ali Shah, Atif Pervez, Azhar Bashir. Role of Dexamethasone in Postoperative Nausea and Vomiting in Laparoscopic Cholecystectomy. P J M H S 2011;5: 1: 89.

15. Amer Riaz Bhutta, Bahzad Akram, Azhar Bashir, Atif Pervez, Ejaz Iqbal, Fara Hassan, Muhammad Arshad Cheema. Preoperative Dexamethasone Reduces Nausea and Vomiting After Laparoscopic Cholecystectomy. P J M H S 2012;6 (3): 699

16. J.J. wang, S.T.Ho, Y, H. Liu, S. C Lee, Y. C. Liu, Y. C. Liao, C. M. Ho. Dexamethasone reduces nausea and vomiting after laparoscopic cholecystectomy. British Journal of anesthesia .1999;83(5):772-5.

17. Ahmadreza Mohtadi, Sholeh Nesioonpour , Amir Salari, Reza Akhondzadeh , Babak Masood Rad, Seyed Mohammad Mehdi Aslani ,The Effect of Single-Dose Administration of Dexamethasone on Postoperative Pain in Patients Undergoing Laparoscopic CholecystectomyAnesth Pain Med. 2014 August; 4(3): e17872.
18. Bisgaard T, Klarskov B, Kehlet $H$, Rosenberg J. Preoperative dexamethasone improvees surgical outcome after laparoscopic cholecystectomy-a randomized double blind placebo controlled trial. Ann Surg 2003;238:651-60.

19. Feo CV, Sortini D, Ragazzi R, De Palma M, Liboni A. Randomized clinical trial of the effect of preoperative dexamethasone on nausea and vomiting after laparoscopic cholecystectomy. Br J Surg. 2006;93:2959.

20. Ionescu D, Mitre C, Leuke L, Bertianu C, Paskarenko G, Puia C, et al. Procedures for preventing postoperative nausea and vomiting after laparoscopic cholecystectomy: dexamethasone and ondansetron. AnesteziolReanimatol2007; 2: 50-2.

21. Kashmiri ZA, Sheikh Z, Haider S. Injection dexamethasone in preventing postoperative nausea and vomiting: a comparison with placebo in the patients undergoing laparoscopic cholecystectomy. J Coll Physicians Surg Pak 2006; 16: 68992.

22. Wakasugi M, Tori M, Shimizu J, Kim YK, Noda T, Dono K, Takeda Y, Yamamoto T, Oshima S, Morimoto Y, Asaoka T, Eguchi H, Nagano H, Mori M, Doki Y; Efficacy of preoperative dexamethasone for postoperative nausea and vomiting after laparoscopic cholecystectomy: a large-scale, multicenter, randomized, double-blind, placebocontrolled trial in Japan. J Hepatobiliary Pancreat Sci. 2015: Nov; 22(11):802-9. 